\title{
(B) Biochemistry \\ COMPARISON OF RHEUMATOID FACTOR (RF) AND ANTI CYCLIC CITRULLINATED PEPTIDE (ANTI -CCP) ANTIBODIES IN EARLY DIAGNOSIS OF RHEUMATOID ARTHRITIS.
}

\section{Reshmy GS* \\ Mrudula EV \\ Sumitha Prabhu \\ PS \\ Dr Ashika MS

\begin{tabular}{l}
\hline Dr Sumithra N \\
Unni \\
\hline Dr Sajitha \\
Krishnan P \\
\hline ABSTRACT \\
\hline
\end{tabular}
human IgG. RF has low specificity as high false positive results are common in the general population. Anti CCP (Anti-cyclic citrullinated peptide) antibody is also a useful marker to diagnose rheumatoid arthritis and included in one of the criteria of the American College of Rheumatology (ACR) /European League against Rheumatism (EULAR) classification of RA. This study is done to compare the diagnostic utility of Anti CCP and RF test in RApatients.

AIM \& OBJECTIVE: Comparison of rheumatoid factor (RF) and Anti cyclic citrullinated peptide (Anti -CCP) antibodies in diagnosis of rheumatoid arthritis- in a tertiary care hospital.

MATERIAL \&METHODS: A total of 70 samples were taken from clinically suspected RA patients over a period of 6 months.RF and AntiCCP was checked in all patients

RESULTS \&DISCUSSION: Out of total 70 samples tested, 51 were seropositive with only Anti CCP positive were 37 (72\%) and only RF positive were $6(11.7 \%)$, whereas both Anti CCP and RF positive both positive were $8(15.6 \%)$

Conclusion: Anti CCP antibody test and RF can be used mutually for early diagnose of Rheumatoid arthritis and suitable management can be initiated to decrease future morbidity.

KEYWORDS : Anti-Cyclic Citrullinated Peptide (Anti CCP) Antibody, Rheumatoid Factor (RF), Rheumatoid Arthritis (RA)

\section{INTRODUCTION}

Rheumatoid Arthritis (RA) is the commonest inflammatory joint disease, affecting nearly $1 \%$ of the adult population worldwide. It is characterized by multiple deformities and is associated with considerable morbidity and mortality ${ }^{1}$. Although the precise aetiology of RA is unknown, there is great role of autoimmunity because several auto antibodies are associated with the disease. Besides the rheumatoid factor (RF), another group of auto antibodies has recently been detected in serum of patients with RA patients: the anti-cyclic citrullinated peptide antibodies (anti CCP $)^{2}$.

Anti peri nuclear factor (APF) and anti keratin antibodies (AKA), two tests known for a long time, have a high specificity of up to $70 \%$ for RA ${ }^{3,4}$.The immunofluoresecnce test could not become much popular in clinical practice, despite high specificity, due to various technical difficulties in doing the assays. Filaggrin was identified as the antigen that was targeted by both these auto antibodies. Antibodies to Sa antigen have also been detected in sera of patients with RA ${ }^{5}$. But APF, AKA, and the anti Sa antibodies target citrullinated proteins 2 . The difficulty of obtaining pure filaggrin antigen has been overcome by development of citrullinated peptides in laboratory. The first generation of ELISA for Anti CCP had high specificity and sensitivity which further increased by the second generation Anti CCP assay

\section{Diagnosis}

Early diagnosis of RA is difficult as most of its symptoms mimic those of many other diseases. There is no unique blood test to confirm the condition

People with rheumatoid arthritis have an elevated erythrocyte sedimentation rate (ESR), C-reactive protein (CRP), which indicate the presence of an inflammatory process in the body. In RA disease auto antibodies are produced such as rheumatoid factor (RF), antiperinuclear factor (APF), ANCA, anti-RA33, anti-flaggerin antibodies, anti-keratin antibodies (AKA), anti-cyclic citrullinated peptide antibodies (CCP), etc.

Among the various auto antibodies, $\mathrm{RF}$ and anti-CCP antibodies are considered useful serological diagnostic markers for RA. Rheumatoid factor (RF) is IgM autoantibody directed against the Fe portion of IgG. Anti-cyclic Citrullinated peptide antibody (Anti-CCP) is autoantibody that is formed after Citrullination.

Anti-cyclic citrullinated peptide antibody (ANTI-CCP) or Anti citrullinated protein antibody (ACAP)

Anti CCP antibodies are a type of auto antibodies targeted against a type of protein called citrullinated protein. Anti-cyclic Citrullinated peptide (anti-CCP) antibody testing is particularly helpful in the diagnosis of rheumatoid arthritis, due to its high specificity, its presence early in the disease process, and the ability to identify the severe patient. Still Anti CCP is not used in our country as a routine test for RA probably due to not much comparative studies or unavailability of this test. Citrullinated extracellular fibrin in the RA synovium may be one of the major auto antigens driving the local immune response. Moreover, more severe disease progression is found in RA patients with anti-CCP antibodies ${ }^{8}$

$\mathrm{RF}$ is antibodies directed to the constant region of immunoglobulins of the IgG class and are found in $70-80 \%$ of patients with RA. IgM RF, the isotype most typically detected, is seen not only in RA, but also in various other conditions like other autoimmune diseases, infections and in up to $5-10 \%$ of healthy individuals ${ }^{9}$. But a combined detection of IgM and IgA RFs in a serum is a strong indicator of RA10. However, IgARFs are not widely available. 


\section{CLINICAL USE OF ANTI-CCPANTIBODIES}

1. Diagnosis of early RA

2. Prediction of severity of the disease

3. Differentiation from other diseases

\section{MATERIAL \& METHOD}

The study was carried out at Amrita Institute of Medical Sciences, Cochin. This was a retrospective laboratory based study. The study period was for 6 months from September 2019 to February 2020.Serum samples were used for the study.

Inclusion criteria: A total of 70 samples from clinically suspected RA patients over a period of 6 months between age of 18- 80 years from both gender were included in the study

Exclusion criteria: Patients with chronic renal failure, malignancy, diabetes mellitus, HIV, HCV and pregnant women

\section{METHOD}

RF determined by latex agglutination method:

ANTI-CCP by the electro chemiluminescence immunoassay "ECLIA".

\section{RESULT}

Table 1: Comparison of RF and anti CCP antibody in clinically suspected RA patients $(n=70)$

\begin{tabular}{|l|l|l|}
\hline & Number & Percentage \\
\hline Anti CCP Positive & 46 & $65 \%$ \\
\hline RF Positive & 14 & $20 \%$ \\
\hline Anti CCP Negative & 25 & $35 \%$ \\
\hline RF Negative & 56 & $80 \%$ \\
\hline
\end{tabular}

Table2: Comparison of positivity of $\mathrm{RF}$ and anti $\mathrm{CCP}(\mathrm{n}=51)$

\begin{tabular}{|l|l|l|}
\hline Only Anti CCP Positive & 37 & $72 \%$ \\
\hline Only RF Positive & 6 & $11.7 \%$ \\
\hline Both Anti CCP and RF Positive & 8 & $15.6 \% \%$ \\
\hline
\end{tabular}

Table3: Distribution of RA patients based on gender $(n=70)$

\begin{tabular}{|l|l|l|}
\hline & Number & Percentage \\
\hline Male & 15 & $21 \%$ \\
\hline Female & 55 & $78 \%$ \\
\hline
\end{tabular}

Table4: Distribution of RA patience based on age $(n=70)$

\begin{tabular}{|l|l|l|}
\hline & Number & Percentage \\
\hline Age between $18-40$ & 16 & $22 \%$ \\
\hline Age between 41-60 & 35 & $50 \%$ \\
\hline Age between $61-80$ & 19 & $27 \%$ \\
\hline
\end{tabular}

Table: 5 Distribution of Anti-CCP in RF negative and positive subjects

\begin{tabular}{|l|l|l|}
\hline & RF Positive & RF Negative \\
\hline Anti CCP Negative & 6 & 19 \\
\hline Anti CCP Positive & 8 & 37 \\
\hline
\end{tabular}

\section{DISCUSSION}

In this present study 70 RA patients were included. Both Anti CCP and RF were checked in all 70 patients. The result showed 46 patients (65\%)were Anti CCP positive while $14(20 \%)$ were RF Positive at the same time $25(35 \%)$ were Anti CCP negative and 56(80\%) were RFnegative. (Table: 1 )

But when considering the 51 seropositive samples the number of patients who were only Anti CCP positive were $37(72 \%)$ and only RF positive were $6(11.7 \%)$, whereas both Anti CCP and RF positive both positive were $8(15.6 \%)$ (Table: 2$)$

Out of the total 70 patients in this study 55 were (78\%) females and 15 were $(21 \%)$ males (Table: 3 ) showing female are more prone to RA than males. Many rheumatic diseases, including rheumatoid arthritis (RA) are more frequent in women than men. The female dominant hormones (estrogen and prolactin) and male dominant hormones (testosterone) have been shown to affect RA susceptibility. Estrogen and prolactin are pro inflammatory whereas testosterone is antiinflammatory in nature. The overall exposure to pro inflammatory hormones for the lifetime of women may be a reason for increased rates of incidence of RA in females than males ${ }^{10}$.

As per this study most common age group was 41-60 (50\%) followed by $61-80(27 \%)$ and least was between $18-40(22 \%)$, (Table: 4$)$ this was similar to the observations of Lena Innala ${ }^{12}$ et al studies in which they found the median age for the onset of RA was 58 years (range $=18$ to 89 years).

Out of 56 RF seronegative samples 37 were Anti CCP positive and 19 were Anti CCP negative. In $14 \mathrm{RF}$ seropositive samples 8 were Anti CCP positive and 6 were Anti CCP negative (Table: 5). Similar findings with our study was shown by Kastbom et al ${ }^{9}$ and Nadeem Afzal et $\mathrm{al}^{11}$.Anti CCP antibodies in RF seronegative patients that indicates that auto antibodies are formed early in the course of RA before RF appear in the serum. Thus making it as an early marker of RA.

Current study 6 RF seropositive patients did not show Anti CCP antibodies, this can indicate that they may be RA negative and might be suffering from other diseases which causes seropositivity thus indicates that RF is not a reliable marker for RA and can be raised in other autoimmune diseases. So the anti-CCP test is thought to be slightly more specific than RF for diagnosing rheumatoid arthritis.

But Anti CCP cannot replace RF completely in diagnosis as well as prognosis of RA. We recommend that Anti CCP antibody test and RF should be used concomitantly to diagnose early RA and can be used in clinical settings so that appropriate management can be initiated to decrease future morbidity.

Thus testing both Anti CCP along with RF may help in a better diagnosis rather than testing for either antibody alone. Those with early arthritis who are RF or anti-CCP antibody positive are at an increased risk of developing RA and erosive joint disease, while those with neither of these markers are less likely to develop joint damage. Thus, earlier intervention with disease modifying anti rheumatic drug therapy may be warranted in those with positive markers, while symptomatic treatment may be appropriate for those lacking both RF and anti-CCP antibodies when first seen.

Thus Anti CCP cannot fully replace RF for the diagnosis and prognosis of RA, but rather from our study, we can suggest that clinically both can be used together for a better and early diagnosis and prognosis of RA. Thus future morbidities can be decreased by taking suitable managements

\section{CONCLUSION}

This study showed that anti-CCP antibodies indeed are good serological markers for RA. Anti-CCP antibodies can be used as the first choice diagnostic test for RA and especially early RA. In RF seronegative patients, anti-CCP can be helpful in confirming the diagn sis of RA. Step up of anti-CCP testing in the ACR's updated 2010 RA classification criteria reveals the clinical value of these tests for the diagnosis of RA patients. However, this does not mean that anti- CCP can replace RF in diagnostic and prognostic testing for RA. For more accurate and early diagnosis a combination of AntiCCP and RF will be better than anti-CCP or RF alone. Considering the ethnic difference, continuous assessment of the diagnostic value of auto antibodies in RA in different ethnic groups is useful and helps revealing the heterogeneous nature of the disease.

Thus Anti CCP antibodies can be a greater promise as a diagnostic marker of RA, as they can be detected very early in RA. They may predict the eventual development into RA when found in undifferentiated arthritis. These antibodies represent an important addition to the diagnostic tools of RA.

However, from the current study, we recommend both Anti CCP antibody test and RF should be used mutually to diagnose early RA and can be used in clinical settings so that appropriate management can be done.

\section{REFERENCE}

1. Pincus T. Long-term outcomes in rheumatoid arthritis. Br J Rheumatol. 1995; 34(2):59 73.

2. Schell kens GA, de Jong BAW, van den hoogen FHJ, van de Putte LBA. Citrulline is an essential constituent of antigenic determinants recognized by rheumatoid arthritis specific auto antibodies. J Clin Invest 1998; 101:273-281.

3. Nienhuis R \& Mandema E. Anew serum factor in patients with rheumatoid arthritis. The anti perinuclear factor. Ann Rheum Dis 1964; 23: 302-305.

4. Young BJ, Mallya RK, Leslie RD, Clark CJ, Hamblin TJ. Anti-keratin antibodies in rheumatoid arthritis. Br Med J. 1979; 2(6182):97-9. 
5. Menard HA, Lapointe E, Rochdi MD, Zhou ZJ. Insights into rheumatoid arthritis derived from the Sa immune system. Arthritis Res $2000 ; 2: 429-432$.

6. Lee DM, Schur PH. Clinical utility of the anti-CCP assaying patients with rheumatic diseases. Ann Rheum Dis. 2003; 62: 870-874.

7. Vallbracht I, Rieber J, Oppermann M et al. Diagnostic and clinical value of anti-cyclic citrullinated peptide antibodies compared with rheumatoid arthritis. Arthritis Rheum 2004; 63(9): 1079-84

8. Van Gaalen FA, van Aken J, Huizinga TW et al. Association between HLA class II genes and autoantibodies to cyclic citrullinated peptides (CCPs) influences the severity of rheumatoid arthritis. Arthritis Rheum. 2004; 50:2113-2121

9. Kastbom A, Strandberg G, Lindroos A, et al. Anti-CCP antibody test predicts the disease course during 3 years in early rheumatoid arthritis (the Swedish TIRA project). Annals of the Rheumatic Diseases 2004; 63:1085-1089.

10. Jacqueline E Oliver and Alan J Silman. Why are women predisposed to autoimmune rheumatic diseases? Arthritis Res Ther. 2009; 11(5): 252-254

11. Nadeem Afzal, Sara Karim, Fazzul-E-Haque Mahmud, Waqas Sami, Maria Arif, Sarwar Abbas.Evaluation of Anti-CCP Antibody for Diagnosis of Rheumatoid Arthritis. Clin. Abbas.Evaluation of Anti-
Lab. 2011; 57:895-899.

12. Lena Innala, Ewa Berglin, Bozena Möller, Lotta Ljung, Torgny Smedby, Anna Södergren, Staffan Magnusson, Solbritt Rantapää-Dahlqvist, and Solveig WållbergJonsson. Age at onset determines severity and choice of treatment in early rheumatoid arthritis: a prospective study. Arthritis Res Ther 2014; 16(2): R94. 